Revista Brasileira de Agricultura Irrigada v.11, nº.6, p. 1797 - 1803, 2017

ISSN 1982-7679 (On-line)

Fortaleza, CE, INOVAGRI - http://www.inovagri.org.br

DOI: $10.7127 /$ rbai.v11n600587

Protocolo 587.17 - 01/03/2017 Aprovado em 23/06/2017

\title{
TRANSPORTE E ADSORÇÃO DE NITRATO E POTÁSSIO EM COLUNAS DE SOLO SOB APLICAÇÃO DE VINHAÇA
}

\author{
João Alberto Lelis Neto ${ }^{1}$, Jarbas Honorio de Miranda ${ }^{2}$, Gilmar Batista Grigolon ${ }^{2}$, Marcos \\ Yassuo Kamogawa ${ }^{2}$, Marconi Batista Teixeira ${ }^{3}$ Nelmício Furtado da Silva ${ }^{4}$
}

\section{RESUMO}

O estudo do transporte dos componentes químicos da vinhaça no perfil do solo é importante, tanto do ponto de vista ambiental quanto econômico. Diante disso, o uso da modelagem computacional torna-se uma ferramenta que permite de maneira precisa e rápida o monitoramento do deslocamento de solutos, sendo importante na prevenção de impactos ambientais. Portanto, a obtenção e o entendimento dos parâmetros de transporte de solutos no solo auxiliam na redução da sua lixiviação para as camadas subsuperficiais. Neste sentido, objetivou-se com o presente trabalho obter os parâmetros de transporte velocidade da água nos poros $(\mathrm{v})$, fator de retardamento $(\mathrm{R})$, dispersividade $(\lambda)$ e coeficiente de dispersão (D), para 0 nitrato e o potássio presentes na vinhaça, em diferentes tipos solos. $\mathrm{O}$ ensaio foi conduzido empregando-se as amostras com estrutura deformada oriundas de dois perfis distintos de solos sob aplicação de vinhaça, coletadas à camada de 0,0-0,20 m. Após a obtenção dos parâmetros de transporte, ajustados pelo programa computacional DISP, notou-se que as curvas de efluentes para ambos os solos e para os íons potássio e nitrato apresentaram semelhança em sua inclinação. Mostrando-se que os resultados obtidos, evidenciaram positivamente os efeitos de adsorção e de deslocamento dos íons nitrato e potássio presentes na vinhaça, principalmente em relação ao íon potássio.

Palavras-chave: curva de efluente, parâmetros de transporte, dinâmica de solutos

\section{NITRATE AND POTASSIUM TRANSPORT AND ADSORPTION IN SOIL COLUMNS UNDER VINASSE APPLICATION}

\footnotetext{
ABSTRACT

${ }^{1}$ Departamento de Engenharia de Biossistemas, Escola Superior de Agricultura "Luiz de Queiroz" (ESALQ), Universidade de São Paulo (USP) - Av. Pádua Dias, 11, C.P. 09, 13418-900, Piracicaba, SP. E-mail: joao_lelis@yahoo.com.br

2 Departamento de Ciências Exatas, Escola Superior de Agricultura “Luiz de Queiroz”.

${ }^{3}$ Eng. Agrônomo, Prof. Dr. em Agronomia, IFGoiano - Campus Rio Verde, e-mail: marconibt@gmail.com

${ }^{4}$ Eng. Agrônomo, Doutorando em Ciências Agrárias - Agronomia, Laboratório de Hidráulica e Irrigação do IF Goiano - Campus Rio Verde, Rio Verde - GO.
} 
The study of transport of chemical components of the vinasse in the soil profile is important, both environmentally and economical. Given this, the use of computational modeling is important as it allows for precise and fast way to monitor the movement of solutes in the prevention of environmental impacts. Therefore, obtaining and understanding the parameters of solute transport in the soil help to reduce leaching to the deep layers. In this sense, our aim was to work with this additional transport parameters of nitrate and potassium via vinasse, as the speed of pore water velocity (v), retardation factor $(R)$, dispersivity $(\lambda)$ and the dispersion coefficient (D) in different soil types. The test was conducted using the undisturbed samples from two distinct profiles of soils collected at $0.0-0.20 \mathrm{~m}$, with application to vinasse. After obtaining the transport parameters set by the computer program DISP, noted that the breakthrough curves for both soils and the potassium and nitrate were similar in slope. The results obtained, the transport parameters showed positive effects of adsorption and displacement of nitrate and potassium ions present in the vinasse, especially in relation to potassium ion.

Keywords: breakthrough curves, transport parameters, solute dynamic.

\section{INTRODUÇÃO}

Atualmente a área plantada de cana-deaçúcar no Brasil está em torno de 8 milhões de hectares, sendo que o Estado de São Paulo possui a maior participação (PROCANA, 2011). Do total da produção de cana-de-açúcar, 336 mil toneladas $(53,8 \%)$ serão destinadas à produção de etanol, gerando um volume total de aproximadamente 28 milhões de litros e, consequentemente, a produção do seu principal subproduto, a vinhaça, também aumentará, podendo alcançar o volume de 332 milhões de litros (CONAB, 2011).

Portanto, o conhecimento dos mecanismos de transporte simultâneo da água e de solutos no solo é essencial para pesquisas que envolvam pontos de vista ambiental e econômico, uma vez que abrange tanto a eficiência do uso da água quanto à aplicação de resíduos agroindustriais na produção agrícola. Esses insumos, quando aplicados acima da capacidade-suporte do solo, podem liberar íons e compostos tóxicos, os quais poderão poluir o solo e as águas subterrâneas. A lixiviação de nutrientes varia com os atributos físicos do solo, como textura, estrutura, profundidade do perfil e, principalmente, porosidade. Entre os atributos químicos que afetam a lixiviação, estão a capacidade de retenção de íons e o pH (SANTOS et al., 2002). O nitrato, por ser um ânion, apresenta uma grande mobilidade e potencial de lixiviação em solos com alto teor de cargas negativas, o que pode acarretar sérios problemas de contaminação de águas subterrâneas. Segundo EDWARDS et al. (1972), alguns íons, quando disponibilizados na solução do solo, são rapidamente deslocados no perfil, como é o caso do nitrogênio que, na forma de íons nitrato, é altamente solúvel em água e apresenta grande mobilidade no solo. No caso do potássio, a importância do seu estudo baseia-se em termos de expressão econômica, visto que é o nutriente em maior abundância na vinhaça, e o conhecimento do seu deslocamento no solo torna-se importante, principalmente para avaliar se esse componente químico encontra-se disponível às plantas, dentro da zona radicular.

Nesse contexto, segundo BORGES JÚNIOR \& FERREIRA (2002), a preocupação com o comportamento de determinados produtos químicos no subsolo tem motivado os pesquisadores a desenvolver modelos teóricos, com o objetivo de descrever os processos físicos envolvidos no transporte de solutos no perfil do solo. Os estudos da dinâmica dos solutos não proporcionam somente um meio de determinação do fluxo no solo, mas devem dar uma explicação física do fenômeno que ocorre na percolação, na troca e adsorção de íons, para o movimento de fertilizantes minerais e outros sais (NIELSEN, 1961).

Dessa forma, o objetivo deste trabalho foi estudar os parâmetros de transporte dos íons potássio e nitrato, mediante a aplicação de 
vinhaça, obtendo-se curvas de distribuição de efluentes, para diferentes tipos de solo, mediante o ajuste numérico das equações em relação aos valores observados experimentalmente, obtendo assim os respectivos parâmetros de transporte de solutos, para aplicações futuras em modelos computacionais.

\section{MATERIAL E MÉTODOS}

O experimento foi conduzido na área experimental do Departamento de Engenharia de Biossistemas da Escola Superior de Agricultura "Luiz de Queiroz" - ESALQ, Universidade de São Paulo - USP, localizada no município de Piracicaba/SP.
Foram confeccionadas junto ao Laboratório de Solos do Departamento de Engenharia de Biossistemas, colunas de PVC de $0,20 \mathrm{~m}$ de altura e $0,05 \mathrm{~m}$ de diâmetro, possuindo um dreno a $0,01 \mathrm{~m}$ abaixo da borda, as quais foram preenchidas com diferentes tipos de solo. Antes do preenchimento das colunas, os dois tipos de solo, classificados como Latossolo Vermelho, Fase arenosa e Nitossolo, Fase argilosa, classificados pelo Sistema Brasileiro de Classificação de Solos, EMBRAPA (2006), foram secos e peneirados, através de uma peneira com uma malha de 0,002 $\mathrm{m}$, para uma melhor acomodação e homogeneização nas colunas, retirando-se o excesso de torrões (Tabela 1).

Tabela 1. Granulometria dos solos utilizados no experimento.

\begin{tabular}{|c|c|c|c|}
\hline \multirow{3}{*}{ Solo } & Argila & Silte & Areia Total \\
\hline & $<0,002 \mathrm{~mm}$ & $0,053-0,002 \mathrm{~mm}$ & $2,00-0,210 \mathrm{~mm}$ \\
\hline & \multicolumn{3}{|c|}{----------------g kg'-1--------------- } \\
\hline Arenoso & 203 & 27 & 770 \\
\hline Argiloso & 381 & 209 & 410 \\
\hline
\end{tabular}

Para que o teste fosse iniciado, primeiramente saturaram-se por capilaridade as colunas com água destilada, processo esse realizado lentamente, no qual as colunas foram alocadas dentro de um balde e, por gotejamento, a água foi adicionada até atingir altura aproximada de $2 / 3$ das colunas. Em seguida, deixaram-se os conjuntos em repouso por um período em torno de 24 horas para garantir a completa saturação e, após esse prazo, deu-se início ao teste, deixando-se passar água destilada com uma carga hidráulica de 0,01 m através das colunas de solo por um período de 36 horas. Após esse período, foi coletado o efluente, calculando-se assim a densidade de fluxo, e foi analisada a concentração dos íons nitrato e potássio para garantir que os íons não estavam presentes na solução do solo que preenchia a coluna (Figuras $1 \mathrm{~A}$ e $1 \mathrm{~B})$.
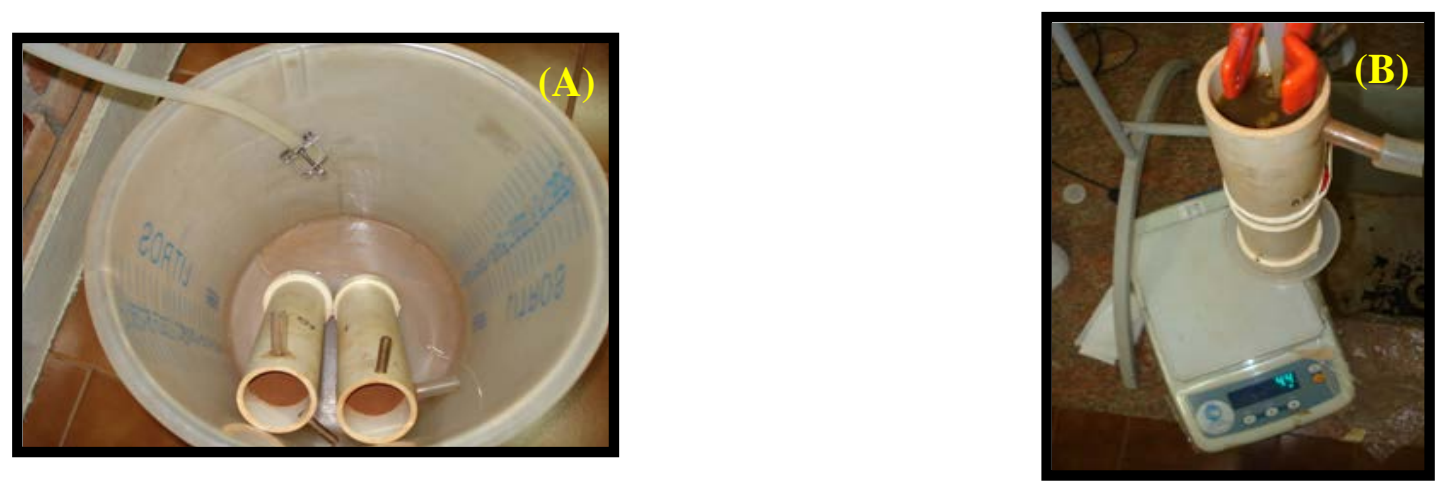

Figura 1. (A) Preparação da coluna de PVC e (B) Início do teste da curva de distribuição de efluentes. 
Após o período da lavagem da coluna, substituiu-se o fornecimento da água destilada pela vinhaça, onde havia uma concentração de $1700 \mathrm{mg} \mathrm{L}^{-1}$ de potássio e $610 \mathrm{mg} \mathrm{L}^{-1}$ de nitrato. A partir desse ponto, iniciou-se a coleta dos volumes da solução com a utilização de frascos de acrílico. A coleta manual dos frascos de acrílico, dos volumes de solução que atravessavam a coluna de solo, representava, individualmente, $10 \mathrm{~mL}$ de efluente coletado, sendo controlado por uma balança eletrônica com precisão de $0,1 \mathrm{~g}$.

$\mathrm{O}$ teste era encerrado quando a concentração inicial da solução $\left(\mathrm{mg} \mathrm{L}^{-1}\right)$, era coletado no final da coluna evidenciando $100 \%$ de solução de aplicação. Para análise das amostras foram utilizados os equipamentos FIA - Flow Injection Analysis e Espectrofotômetro de chama para análise de nitrato e potássio, respectivamente.

Em seguida, utilizou-se o programa computacional "DISP", para fazer o ajuste das curvas de distribuição de efluentes (BORGES JÚNIOR \& FERREIRA, 2002), desenvolvido em linguagem de programação Delphi 3 , que consiste em adotar os estimadores que minimizam a soma dos quadrados dos desvios (Rs), entre os valores estimados e observados da concentração relativa $\mathrm{Ce}=\mathrm{C} / \mathrm{Co}$, em que $\mathrm{C}$ é concentração coletada do efluente e Co é a

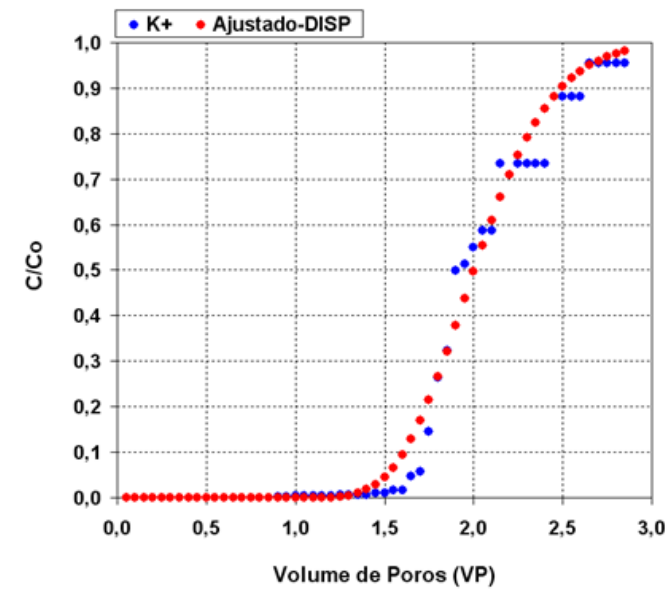

concentração inicial em relação ao número do volume de poros (VP). Na minimização de Rs, utiliza o método de Marquardt (SEBER e WILD, 1983; CUNHA, 1993), que requer a obtenção de derivadas parciais em relação aos parâmetros Número de Peclet (P) e Fator de retardamento $(\mathrm{R})$, para número de volumes de poros determinados experimentalmente sendo as derivadas calculadas por meio de métodos numéricos.

\section{RESULTADOS E DISCUSSÃO}

Ao analisar a influência do solo na curva de efluente da vinhaça, observou-se que no solo argiloso, tanto o potássio quanto o nitrato, houve um maior deslocamento das curvas de efluente para a direita, quando comparados com o solo arenoso, indicando que os íons potássio e nitrato foram retidos no solo, com maior intensidade. No solo argiloso os íons apresentaram um maior efeito de adsorção, necessitando de uma quantidade de no mínimo 2 volumes de poros (VP) e no máximo 3 volumes de poros (VP), para que a concentração inicial fosse atingida, ao contrário do solo arenoso que os íons ficaram em torno de 1,8 VP, não ultrapassando 2 VP (Figuras 2 e 3).

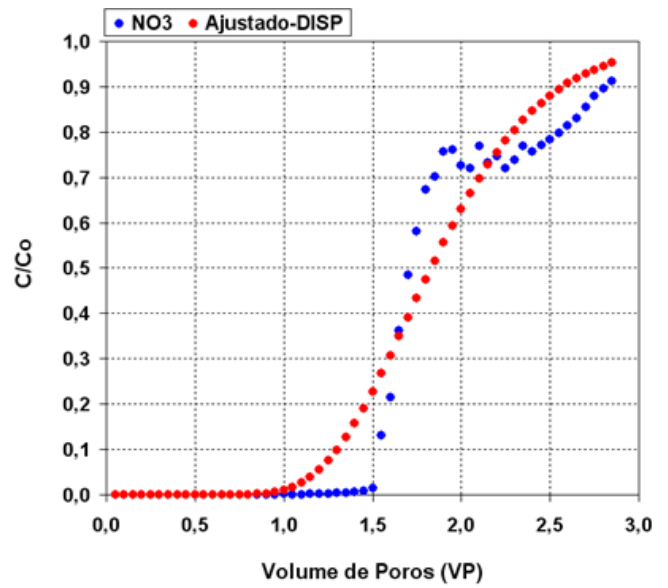

Figura 2. Curvas de distribuição de efluentes elaboradas com vinhaça, solo argiloso, para os íons potássio e nitrato. 

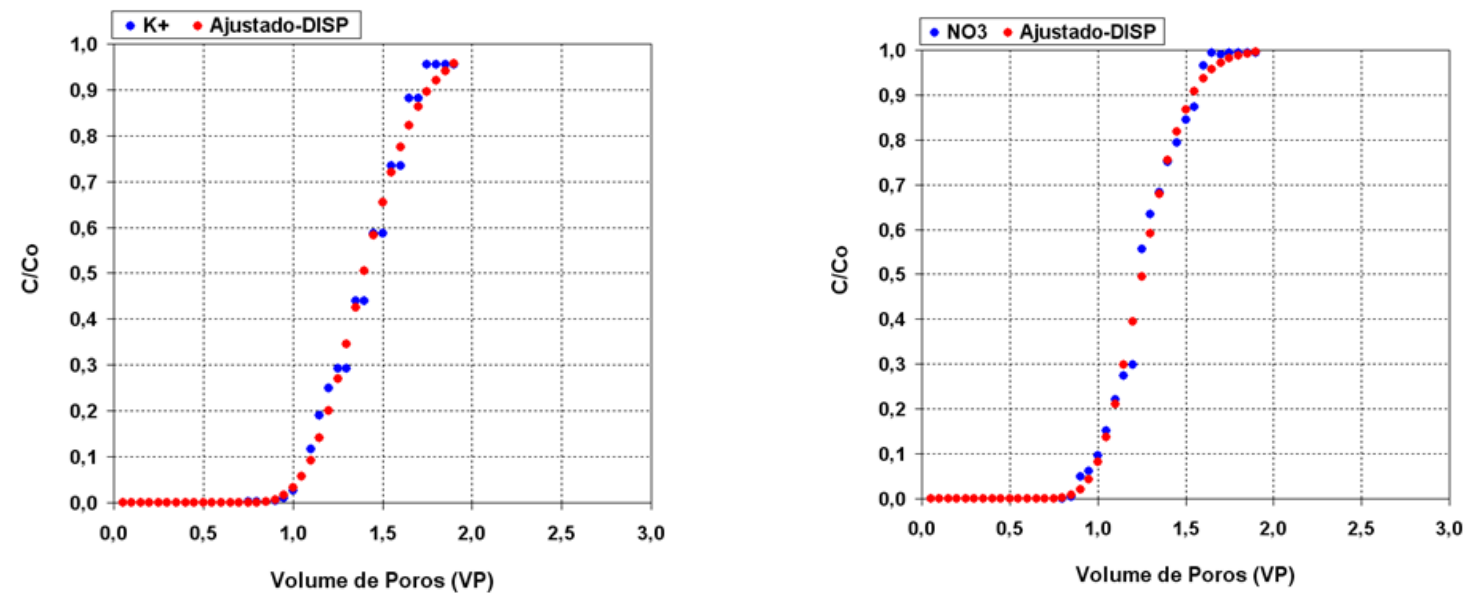

Figura 3. Curvas de distribuição de efluentes elaboradas com vinhaça, solo arenoso, para os íons potássio e nitrato.

No solo argiloso, observou-se que, para o potássio, houve um maior deslocamento das curvas de efluente para a direita, indicando que os íons de potássio foram retidos no solo com maior intensidade em relação aos íons de nitrato. O íon potássio apresentou uma maior relação quanto ao ajuste do programa, sendo que a concentração inicial foi observada com 1,5 volumes de poros (VP) e necessitando de uma quantidade de 3,0 VP para atingir a concentração máxima relativa, explicado por seu caráter catiônico, o potássio é tanto mais facilmente adsorvido à matriz do solo quanto maior for à capacidade de troca de cátions desse solo (MELO et al., 2006).

Em experimento de deslocamento miscível em um Latossolo Vermelho, RIVERA et al. (2006) concluíram que há interação do potássio com a matriz do solo, uma vez que a distribuição do elemento ficou restrita às camadas superficiais do bulbo úmido, fato confirmado pelo elevado coeficiente de retardamento $(\mathrm{R}=4,73)$. Resultados obtidos por outros autores, também em Latossolo, corroboram a tese da interação potássio com a matriz do solo (MIRANDA et al., 2005; MELO et al., 2006; ARAÚJO et al., 2007; GONÇALVES et al., 2008; PINHO, 2009).
Por outro lado, para ambos os íons no solo arenoso, houve uma inclinação acentuada da curva ficando abaixo de $1 \mathrm{VP}$, mostrando-se uma baixa interação soluto-solo. Este resultado está de acordo com o que foi proposto por NIELSEN E BIGGAR (1962), em que o número de volume de poros correspondente à concentração relativa de 0,5 é uma primeira indicação, no sentido da existência ou não, de interações soluto-solo.

$\mathrm{O}$ íon nitrato em ambos os solos apresentou certa repulsão entre o solo e o nitrato estando relacionada possivelmente com a predominância de cargas negativas. Entretanto, o programa subestimou o seu inicio ocorrendo quando ainda tinha $1,0 \mathrm{VP}$, sendo, que o observado iniciou-se com 1,5 VP, terminando próximo aos 3,0 VP, podendo ser compreendido pelo fato que a vinhaça é uma mistura composta onde detém de vários elementos e uma porcentagem significativa de matéria orgânica.

Enquanto as curvas de distribuição de efluentes caracterizam o deslocamento miscível das soluções, os parâmetros de transporte, obtidos por meio de seus ajustes, quantificam esta movimentação (Tabela 2).

Tabela 2. Parâmetros de transporte do potássio e nitrato: fator de retardamento (R), coeficiente de dispersão (D), número de Peclet (P), velocidade da água nos poros (v), coeficiente de dispersividade calculado em função do número de Peclet $(\lambda)$, para diferentes solos submetidos à simulação.

\begin{tabular}{cccccc}
\hline \multicolumn{5}{c}{ Parâmetros de transporte do potássio } \\
\hline Solo & $\mathrm{R}$ & $\begin{array}{c}\mathrm{D} \\
\left(\mathrm{cm}^{2} \mathrm{~min}^{-1}\right)\end{array}$ & $\mathrm{P}$ & $\begin{array}{c}\mathrm{v}(\mathrm{P}) \\
(\mathrm{cm} \mathrm{min})\end{array}$ & $\lambda(\mathrm{P})$ \\
& & & \\
\hline
\end{tabular}


Lelis Neto et al.

\begin{tabular}{cccccc} 
Arenoso & 1,396 & 4,0912 & 61,31 & 12,54 & 0,326 \\
Argiloso & 2,032 & 7,737 & 67,86 & 26,25 & 0,295 \\
\hline \multicolumn{5}{c}{ Parâmetros de transporte do nitrato } \\
\hline Solo & $\mathrm{R}$ & $\mathrm{D}$ & $\mathrm{P}$ & $\mathrm{v}(\mathrm{P})$ & $\lambda(\mathrm{P})$ \\
& & $\left(\mathrm{cm}^{2} \mathrm{~min}^{-1}\right)$ & & $\left(\mathrm{cm} \mathrm{min}^{-1}\right)$ & \\
Arenoso & 1,253 & 3,2597 & 76,46 & 12,46 & 0,262 \\
Argiloso & 1,896 & 19,0424 & 27,57 & 26,25 & 0,725 \\
\hline
\end{tabular}

Os parâmetros de transporte dos íons estudados foram obtidos mediante a aplicação do software DISP, cujos valores mais altos dos coeficientes de dispersão-difusão, ocorreram em relação ao solo argiloso. $\mathrm{O}$ fator de retardamento $(\mathrm{R})$, por ser uma característica que retrata a capacidade do solo em reter solutos, à medida que o fluxo de massa avança, depende das interações entre as fases líquida e sólida que ocorrem durante a percolação. Os valores de $\mathrm{R}$ encontrados para os íons nitrato e potássio foram bem próximos para os solos estudados.

Porém, observou-se em relação ao parâmetro de transporte - dispersão (D), para o íon potássio não foram encontradas diferenças entre os solos, mas para o íon nitrato houve um aumento entre os valores, obtendo um valor superior para o solo argiloso. Quimicamente, por se tratar de um ânion, o nitrato é fortemente repelido pelas cargas negativas dos colóides do solo, daí a lixiviação ser o principal processo envolvido na perda de $\mathrm{NO}^{3-}$ na maioria dos solos (PIOVESAN et al., 2009).

Os valores obtidos de número de Peclet (P) foram semelhantes entre os solos quando analisado o íon potássio, porém ao analisar o íon nitrato houve um aumento em relação do solo arenoso, concordando com PINHO (2009), que encontrou diferença na sua dissertação trabalhando com diferentes tipos de solo classificados como Latossolo Vermelho e Nitossolo confirmando a maior velocidade de advecção no primeiro solo, devida à predominância de macroporos, responsáveis diretos pela condução da água no solo durante os processos de infiltração, conforme LIBARDI (2005).
Os parâmetros de transporte evidenciaram positivamente os efeitos de adsorção e de deslocamento dos íons nitrato e potássio presentes na vinhaça, principalmente em relação ao solo argiloso.

\section{AGRADECIMENTOS}

Os autores agradecem ao Conselho Nacional de Desenvolvimento Científico e Tecnológico (CNPq) e à Fundação de Amparo à Pesquisa do Estado de São Paulo (FAPESP), pelo apoio financeiro a esta pesquisa, através do Instituto Nacional de Ciência e Tecnologia em Engenharia da Irrigação (INCTEI).

\section{REFERÊNCIAS BIBLIOGRÁFICAS}

ARAUJO, C.A.S.; SILVA, D.J.; DAMASCENO, F.C.; ANJOS, J.B. Determinação do fator de retardamento para potássio em solo cultivado com videira. In: CONGRESSO NACIONAL DE IRRIGAÇÃO E DRENAGEM, 17., 2007, Mossoró. Resumos... Mossoró: ABID, 2007. 1 CD-ROM.

BORGES JÚNIOR, J.C. F.; FERREIRA, P. A. Programa Computacional para cálculo de parâmetros do transporte de solutos em deslocamento de fluídos miscíveis. In: CONGRESSO BRASILEIRO DE ENGENHARIA AGRÍCOLA, 31., 2002, Salvador. Anais... Jaboticabal: SBEA, 2002. p 1-4.

COMPANHIA NACIONAL DE ABASTECIMENTO. ACOMPANHAMENTO DE SAFRA BRASILEIRA: cana-de-açúcar, terceiro levantamento, janeiro/2011

\section{CONCLUSÃO}


Companhia Nacional de Abastecimento. Brasília: Conab 2011.

CUNHA, C. Métodos numéricos para as engenharias e ciências aplicadas. Campinas, SP: Editora da Unicamp, 1993. 265p.

EDWARDS, D.M; FISCHBACH, P.E; YOUNG, L. L. Movement of nitrate under irrigated agriculture. Transactions of the ASAE, St. Joseph v.15, n.1, p. 73-75, 1972.

EMBRAPA - Empresa Brasileira de Pesquisa Agropecuária. Centro Nacional de Pesquisa de Solos. Sistema brasileiro de classificação de solos. Rio de Janeiro: EMBRAPA, 2006. 306p.

GONÇALVES, A.D.M.A; MIRANDA, J.H.; ROSSI, P.; SABADIN, J.F.G.; KAMOGAWA, M.Y. Temperature effect in potassium and nitrate ions in soil transport. Engenharia Agrícola, Jaboticabal, v. 28, n. 3, p. 438-447, 2008.

LIBARDI, P.L. Dinâmica da água no solo. São Paulo: EDUSP, 2005. 329 p.

MELO, R.F.; FERREIRA, P.A.; MATOS, A.T.; RUIZ, H.A.; OLIVEIRA, L.B. Deslocamento miscível de cátions básicos provenientes da água residuária de mandioca em colunas de solo. Revista Brasileira de Engenharia Agrícola e Ambiental, Campina Grande, v. 10, n. 2, p. 456-465, 2006.

NIELSEN, D.R.; BIGGAR, J.W. Miscible displacement in soils: I. Experimental Information. Soil Science Society of America Proceedings, Madison, v. 25, n. 1, p. 1-5, 1961.

NIELSEN, D.R.; BIGGAR, J.W. Miscible displacement: III. Theoretical Considerations.
Soil Science Society of America Journal. Madison, v. 26, n. 1, p. 216-221. 1962.

PIOVESAN, R.P.; FAVARETTO, N.; PAULETTI, V.; MOTTA, A.C.V.; REISSMAN, C.B. Perdas de nutrientes via subsuperfície em colunas de solo sob fertilização mineral e orgânica. Revista Brasileira de Ciência do Solo, Viçosa, v. 33, n. 1, p. 757-766, 2009.

PINHO, R. E. da C. Teores de água e solutos no solo: desempenho e sensibilidade do modelo Hydrus-1D. Dissertação (Mestrado em Física do Ambiente Agrícola) Escola Superior de Agricultura "Luiz de Queiroz". Piracicaba, 2009. 81 p.

PROCANA. Disponível em: <http://www.jornalcana.com.br/>. Acesso em: 14 outubro. 2011.

RIVERA, R.N.C.; DUARTE, S.N.; MIRANDA, J.H.; BOTREL, T.A. Modelagem da dinâmica do potássio no solo sob irrigação por gotejamento: validação do modelo. Engenharia Agrícola, Jaboticabal, v. 26, n. 2, p. 388-394, 2006.

ROSSI, P.; MIRANDA, J.H.; DUARTE, S.N. Curvas de distribuição de efluentes do íon nitrato em amostras de solo deformadas e indeformadas. Engenharia Agrícola, Jaboticabal, v. 27, n. 3, p. 675-682, 2007.

SANTOS, A.B.; FAGERIA, N.K.; ZIMMERMANN, F.J.P. Atributos químicos do solo afetado pelo manejo da água e do fertilizante potássico na cultura de arroz irrigado. Revista Brasileira de Engenharia Agrícola e Ambiental, Campinas Grande, v.6, n.1, p.12-16, 2002. 